

\section{Company Maturity Matrix}

\section{Olga Eckardt}

\section{Introduction}

Since the Software Engineering Institute has launched the Capability Maturity Model (CMM) more than twenty-five years ago (Paulk, 1993), several maturity models have been proposed by researchers and practitioners across multiple application domains. Some notable examples are "supply chain management process maturity model" by Lockamy and McCormack (2004), "project management maturity model" by Crawford (2006), "business process management maturity model" by Bruin, and Rosemann (2005) and "risk maturity model" by Hillson (1997). Basic purpose of such models is to represent stage-based evolution and describe stages as well as maturation paths.

In this research, "Company Maturity" is viewed as strength of the relationship between cumulative experience of the company as ability to take right decisions and anti-fragile as ability to react on uncertainty. In the current managerial literature, these two dimensions are not cross-fertilizing. "Experience" is observed typically from human capital perspective and not cross-influenced with other dimensions.

Anti-fragile as a concept appeared in 2010 and was developed in more detail through 2012-2014 by Nasim Taleb, and it is still not used very widely. Application of this is mainly shown in financial sphere (Aven 2015, White 2013). Nevertheless, usage of the concept as a tool, even isolated, in strategical decision taking (Derbyshire \& Wright 2014) or engineering (Jones, 2014, Monperrus, 2017) starts to take place more and more. Usage of this as one of dimensions for better understanding of multifactor models will come in general practice in nearest future.

\section{Research Methodology and Design}

Any model development is going on the direction from one-factor dependencies to multi factor. One of the special cases of multi-factor models is 2-factor model represented as matrix. This type of model representation is well known and widely used for example by Boston Consulting Group Matrix (Henderson. 1979), Balanced Score Card (Norton, Kaplan 2001), SWOT (Pickton, Wright,1998) or Ansoff Matrix (Ansoff, 1957). These examples show a model evolution direction that is widely used in economical science and prove the concept that matrix tools can be extremely useful in management analyses.

General Design Principles for Maturity Models is described based on an extensive review of maturity model-related literature by Pöppelbu and Röglinger (2011). This article changes analysing and developing of maturity models from "Descriptive, prescriptive, and comparative" to "Basic, Descriptive, Prescriptive" for the purpose of use. Taking into account the previously mentioned principal as basement of maturity model development, the author is presenting the Company Maturity Matrix and its' development in the next section.

\section{Model Description}

To make a representation of Company Maturity Matrix, the author has defined a specific coordinate system. Keeping in mind previously described approaches, where one was "Anti-Fragile" - is the ability from company side to react on the previously un-known treats, when something happens suddenly. On the other hand, "Experience" - is ability of company to have a standard solution for the standard situation. "Experience" in this case can come not only from own company history, but as well from external sources or internal persons. The author is focused on developing a matrix. Further application of this matrix will be described and presented separately.

As a result of the previously mentioned approach, the author built a matrix where on one axe "Anti-Fragile" is positioned and on the other axe "Experience (proficiency)" is positioned. Roughly classifying "AntiFragile" to low and high, and "Experience (proficiency)" to low and high, we get a 4 square matrix, as shown in Table 1 below.

Table 1: Company Maturity Matrix

\begin{tabular}{|c|c|c|}
\hline \multirow{2}{*}{ Anti- } & \multicolumn{2}{|c|}{ Experience (cumulative value) } \\
\hline \multirow{2}{*}{ Fragile } & $\begin{array}{c}\text { Teen-ager } \\
\text { High Anti-Fragile - } \\
\text { Low Experience } \\
\text { (proficiency) }\end{array}$ & $\begin{array}{c}\text { Adult } \\
\text { (Age as biggest } \\
\text { efficiency)- } \\
\text { High Anti-Fragile - } \\
\text { High Experience } \\
\text { (proficiency) }\end{array}$ \\
\cline { 2 - 3 } & $\begin{array}{c}\text { Bow Anti-Fragile - } \\
\text { Low Experience } \\
\text { (proficiency) }\end{array}$ & $\begin{array}{c}\text { Old-man } \\
\text { Low Anti-Fragile - } \\
\text { High Experience } \\
\text { (proficiency) }\end{array}$ \\
\hline
\end{tabular}

Resource: Developed by the author

Each square will be described below as a separated state of company where the author is referring to a human organism life cycle. To make this reference as transparent as possible, names for squares are used correspondingly.

\section{- Baby}

The starting point of the analyses will be the low left corner with the box "Baby- Low Anti-Fragile - Low Experience (proficiency)". Looking from the perspective of experience, as for the real small baby, we consider that there is a staff/company culture, which has no big experience. It is important to clarify one point - start-up companies or new established companies are not necessarily in this position. The experience of the 
company can come with experienced staff from other companies, good mentoring, professional and experienced managers, and owners with big experience who are deeply involved in the processes. On the other hand weak corporate culture, unmotivated staff, big staff rotation could be a factor that leads to low experience.

Parallel to this issue, a company would not be able to survive under spontaneous changes in its surrounding. Here, survival buffer is too low and the company is in the area of "baby". The outcome of the situation is that, the company has no possibility to react quickly on environmental changes; even critical fluctuations could be detected too late. "Low Experience" - means in case of threats to have no pull of standard solution, this will be automatically implemented. This lack of experience or not enough deep situation understanding leads to giving fast reactions on the situation to avert danger.

\section{- Teen-ager}

This is the area where experience is still low as in the previous case, but anti-fragility is much higher. This could be achieved by higher speed and flexibility of reaction on any changes. What is more important in this case is that, information flow has no barriers. All valid (and probably non-valid as well) information is rapidly and transparently reaching to decision makers. In such a situation even with less experience, the time for taking a decision could be enough. However this requests that, all deals are going on the fingertips of company leaders.

"Low Experience" as the degree on this axe means - no availability of standard solution that will be automatically implemented in case threat is known, or understood well enough. But the situation will appear as if every new challenge is really new, and indeed needs to be investigated, even if a good and stable solution is existing in the industry or cross industry, but unknown in the particular company. This way of dealing with threats and opportunities might cause problems such as noneffective spending of resources to look after a wellknown problem-solution, similar to reinventing the wheel.

\section{- Adult}

The "Adult" is an "ideal" area of company life. "Experience" as a result of internally achieved and shared intelligence, challenged and extended with external knowledge from merging and acquisition, leads to a huge portfolio of standard reactions in demanding situations, which can be freely accessed as the intellectual capital of company. Getting on board the "right" people, motivating the staff to interact and share information actively, providing transparent decisions, playing as a team instead of fighting for power in groups with political games are critical issues at this point. Ability to have pull of a standard answer on possible changes and situations based on diverse team experience, freedom of offering ways and solutions to be heard are all classified as characteristics of intellectual capital. This leads to high speed and flexibility to react. All deals are going on the fingertips of company leaders. Experience is enough to solve problems and detect them on the earliest step.

\section{- Old-man}

There is a huge amount of experience here, not only because of the history, but as well resulting from a lot of experienced personnel who are working in the company. Nevertheless, possibilities to react on the threats and opportunities are limited. Most recent information coming to the head of the company is quite slow. This is because, existing corporate culture and common routines (best practices) start to counteract to the changes. System tries to come back in the last stable state. Analytics is developed perfectly. But until it is reaching to the decision-maker, analytics already needs to be renewed.

\section{Conclusion and Discussions}

A general framework of possible influences between cumulative company experience and antifragility has been presented, in order to better understand a life cycle of company and apply this as a tool to standard managerial practices.

Talking about company strategies, right or wrong steps, controlling systems or management styles, we need to keep in mind that each company has its own life cycle as shown in the matrix. Each phase has its own challenges and risks, different levels of stability and different reactions on practice. This tool intends to help stakeholders to understand that, key factors for a positive development of company are different in different phases.

This research motivates for further research to find different possibilities of managing a company in these different phases. It intends to change the point of view on management of the company from "looking best solution for all time being" to "understanding on which maturity level the company is, and choosing appropriate management solutions accordingly to the situation". This close look to the situation changes company management approaches from static to dynamic, and allows accepting that "good" or "bad" decision is not only a matter of environmental condition, bus as well a matter of internal maturity.

\section{References}

Ansoff, H. I. (1957). Strategies for diversification. Harvard business review, 35(5), 113-124.

Aven, T. (2015). The concept of antifragility and its implications for the practice of risk analysis. Risk analysis, 35(3), 476-483.

Corbin, J. M. and Strauss, A. (1990). Grounded theory research: Procedures, canons, and evaluative criteria. Qualitative sociology, 13(1), 3-21. 
Crawford, J. K. (2006). Project management maturity model. Auerbach Publications.

De Bruin, T. and Rosemann, M. (2005). Towards a business process management maturity model.

Derbyshire, J. and Wright, G. (2014). Preparing for the future: development of an 'antifragile'methodology that complements scenario planning by omitting causation. Technological Forecasting and Social Change, 82, 215-225.

Henderson, B. D. (1979). The product portfolio: growth share matrix of the Boston Consulting Group. The strategy process: Concepts, contexts, cases, 678-680.

Hillson, D. A. (1997). Towards a risk maturity model. The International Journal of Project \& Business Risk Management, 1(1), 35-45.

Jones, K. H. (2014). Engineering antifragile systems: A change in design philosophy. Procedia computer science, 32 , 870-875.

Kaplan, R. S. and Norton, D. P. (2001). The strategyfocused organization: How balanced scorecard companies thrive in the new business environment. Harvard Business Press.

Lockamy III, A., and McCormack, K. (2004). The development of a supply chain management process maturity model using the concepts of business process orientation. Supply Chain Management: An International Journal, 9(4), 272-278.

Monperrus, M. (2017, April). Principles of antifragile software. In Companion to the first International Conference on the Art, Science and Engineering of Programming (p. 32). ACM.

Paulk, M. (1993). Capability maturity model for software. Encyclopedia of Software Engineering.
Pickton, D. W. and Wright, S. (1998). What's swot in strategic analysis?. Strategic change, 7(2), 101109.

Pöppelbuß, J. and Röglinger, M. (2011, June). What makes a useful maturity model? a framework of general design principles for maturity models and its demonstration in business process management. In ECIS (p. 28).

Strauss, A. and Corbin, J. M. (1990). Basics of qualitative research: Grounded theory procedures and techniques. Sage Publications, Inc.

Taleb, N. N. (2012). Antifragile: how to live in a world we don't understand (Vol. 3). London: Allen Lane.

Taleb, N. N. and Douady, R. (2013). Mathematical definition, mapping, and detection of (anti) fragility. Quantitative Finance, 13(11), 16771689.

White, L. H. (2013). Antifragile banking and monetary systems. Cato J., 33, 471. 